\title{
HISTÓRIAS EM QUADRINHOS: BARREIRAS PARA A REPRESENTAÇÃO DOCUMENTAL
}

\section{Resumo}

Visa discutir as dificuldades para a representação documental de histórias em quadrinhos (HQs), como a presença da imagem e o reconhecimento como meio de comunicação de massa, abordando as definições e características das obras em quadrinhos e como se apresenta a informação neste contexto imagético-textual. Aponta como o desconhecimento em nível iconográfico, de acordo com a proposta de análise da imagem de Panofsky, influencia no processo de representação das HQs. Através de revisão de literatura, conclui que há um subaproveitamento deste tipo de coleção nas bibliotecas e unidades de informação, em parte devido a carência de estudos sobre o tema na área de Ciência da Informação, o que permitiria potencializar o uso dos seus recursos informativos.

Palavras-chave: Histórias em quadrinhos; Representação documental; Informação; Imagem; Comunicação.

COMICS: BARRIERS TO DOCUMENTARY REPRESENTATION

\section{Abstract}

It aims at debating on difficulties related to documentary representation of comics, such as the image presence, and the recognition as mean of mass communication. It approaches definitions and characteristics of comics and how information in such textual imagetic context would be brought forward. It points out how recognition in iconographic level, in accordance with Panofsky, has influence on comics representation process. It concludes that there is a subutilisation of such type of collection in information units and libraries, due partly to the lack of studies on such topics in the field of Information Science, which would enable to potentialize the use of their own informative resources.

Keywords: Comics; Documentary representation; Information; Image; Communication.
Edvaldo de Souza

Graduado em Biblioteconomia e Documentação pela UFBA. Técnico de Processo Operacional do Núcleo de Documentação e Informação do

SENAI/CETIND

souzasouzavaldo@gmail.com

Lídia Brandão Toutain Doutora em Filosofia pela Universidad de León. Diretora do Instituto de Ciência da Informação da Universidade Federal da Bahia(ICl/UFBA). Ibrandao@ufba.br 


\section{INTRODUÇÃO}

A prori, "imagens seqüenciais de uma história" são os termos mais encontrados na maioria das definições sobre os quadrinhos. Uma análise mais atenta demonstra que, na maioria, elas constituem um conceito que abrange outras formas de expressão humana, como a animação, e até a palavra escrita, formada de signos linguísticos sequenciais.

Na busca de uma definição mais específica para os quadrinhos, McCloud (1995, p. 9) sugere designar as HQs como "imagens pictóricas e outras justapostas em sequência deliberada destinadas a transmitir informações e/ou a produzir uma resposta no espectador".

Assim, as imagens são justapostas, com o passado, presente e futuro do mesmo evento se apresentando em um só espaço, proporcionando ao seu leitor autonomia e domínio do timing da ação não encontrados em outras formas de comunicação, o continuum transcorrendo de acordo com sua vontade, só encontrando barreiras na velocidade do olhar.

A apropriação do texto pelo leitor implica a produção de sentido, baseada na experiência individual de cada leitor. Leitura é construção de sentidos, de significados (DUMONT, 2006 apud MAIMONE, 2008).

Por vezes, os quadrinhos são vistos como outro nível de leitura:

As histórias em quadrinhos comunicam numa linguagem que se vale de experiência visual comum ao criador e ao público. Pode-se esperar dos leitores modernos uma compreensão fácil da mistura imagem - palavra e da tradicional decodificação do texto. A história em quadrinhos pode ser chamada "leitura" num sentido mais amplo que o comumente aplicado ao termo. (EISNER, 1989, p. 7).

O efeito biológico que os quadrinhos, ao serem consumidos, exercem sobre o cérebro do leitor, é um fator preponderante. Seu poder de transmissão de mensagens, e, consequentemente, a razão do fascínio que exercem, reside no fato de enviar, simultaneamente, ao cérebro do leitor, dois códigos diferentes: texto e imagem.

Graças à tomografia computadorizada, já se sabe que as imagens são lidas como informação imagética pelo hemisfério direito do cérebro, enquanto que os fonemas pelo esquerdo. $O$ ensino tradicional, porém, se apóia na física clássica, linear e fragmentada, com base na informação escrita científica, estimulando, portanto, o hemisfério esquerdo, em detrimento ao 
direito, ignorando as informações intersubjetivas, como os desenhos (grifo nosso). (ANDRAUS, 2006, p. vi).

Esta combinação é mais eficaz que o uso de apenas um dos códigos usados isoladamente, não sendo apenas usados para complementar-se uma a outra, mas além, criam "um novo nível de comunicação, que amplia a possibilidade de compreensão do conteúdo" (MINISTÉRIO DA EDUCAÇÃO, 1998 apud VERGUEIRO, 2007, p. 22).

\section{A BARREIRA DO CAMPO DE ESTUDO}

Um estudo em Ciência da Informação sobre conteúdo informacional nas histórias em quadrinhos, meio de comunicação de massa, implica quase sempre na troca hermenêutica com a área de Ciências da Comunicação.

A problematização da questão pode ser exemplificada com um jornal, quando este atravessa o campo da comunicação e passa ao da informação (e vice-versa), obtendo o estatuto de parte de um objeto de pesquisa (grifo do autor) (STUMPF; WEBER, 2003).

O fato de ser um produto da comunicação de massa fez dos quadrinhos um objeto de análise das Ciências da Comunicação, impedindo-o, durante muito tempo, de ser adotado como alvo de investigação de outras áreas do conhecimento, como Artes e Ciências da Informação.

O fato de um objeto ser alvo de pesquisa de diferentes áreas do conhecimento pode antes inibir o pleno desenvolvimento das discussões do que multiplicar a quantidade de estudos; a alternativa de estudos multidisciplinares requer um bom diálogo nas comunidades de conhecimento a fim de possibilitar a ambos a assimilação da carga conceitual construída na outra área, com suas terminologias e teorias específicas.

A partir dos anos $80^{1}$, com a crescente incorporação de fatos reais e temáticas adultas nas HQs, o seu conteúdo informativo passou a atrair os especialistas da informação, que não encontraram literatura específica sobre o tema e importaram vários conceitos

1 Quando artistas europeus, na maioria britânicos, passaram a trabalhar para grandes editoras norteamericanas de quadrinhos, elevando o nível das histórias com tramas complexas e realísticas. Um dos trabalhos deste período, Watchmen, de Alan Moore e Dave Gibbons, foi considerada pela Time como um dos cem melhores romances de todos os tempos e aborda, entre outras temáticas, a tensão da Guerra Fria e os regimes autoritários.

PontodeAcesso, Salvador, v. 4, n. 1, p. 78-95, abril. 2010.

www.pontodeacesso.ici.ufba.br 
adotados em Comunicação a fim de desenvolver seus próprios estudos . Porém, o estigma de produto de comunicação de massa ainda perseguiria os quadrinhos durante as abordagens sob o novo prisma. "Uma comunicação, premente ou sedutora demais, impede uma informação verdadeira de descolar ou de extrair-se da comunicação" (BOUGNOUX, 1999, p. 143). ${ }^{2}$

A posição fronteiriça, entre Comunicação e Informação, que os quadrinhos informativos ocupam, ganha contornos mais nítidos no contexto atual, onde cada vez mais são percebidos como fruto de uma cultura contemporânea, pois as duas áreas do conhecimento "têm sido utilizadas como referência para demarcar a contemporaneidade" (STUMPF; WEBER, 2003, p. 121), levantando questões paradoxais e epistemológicas.

Não cabe ao escopo do presente trabalho suscitar estas questões em nível mais amplo, porém cabe distinguir onde elas convergem em relação às histórias em quadrinhos e explicitar como se coadunam no sentido de tornar mais complexa a tarefa dos pesquisadores.

A interdisciplinaridade é prevista pelos estudiosos. Le Coadic (1996, p. 109) afirma ser a informação, cujo conteúdo é marcado pelo "selo da interdisciplinaridade", um recurso vital do qual não se mediu suficientemente "a extensão dos usos e não-usos, por falta de atenção com seus usuários." Esta desatenção ocorre com os leitores de quadrinhos, que, nos ambientes das bibliotecas de qualquer tipo (pública, universitária, especializada, escolar), não são vistos, sob a ótica do bibliotecário, como sujeitos receptores de informação durante suas leituras de HQs, e sim como agentes passivos no famigerado processo de comunicação de massa.

A questão deve residir no tipo de informação que os leitores de quadrinhos estão recebendo, e não sobre a existência ou não dela. Além disso, como conceito, o termo informação "não sofre de desemprego" (McGARRY, 1999, p. 2) e, a depender do conceito adotado, a presença de conteúdo informativo pode ser caracterizada de diferentes maneiras, porém dificilmente descartada; não admiti-la nos quadrinhos equivaleria a afirmar que obras de literatura não são fontes de informação.

É evidente que o usuário não procura os quadrinhos com o objetivo principal de satisfazer sua necessidade de informação, porém esta ocorre sub-repticiamente, de forma

\footnotetext{
${ }^{2} \mathrm{O}$ autor menciona algumas situações para que isto ocorra, como infiltração publicitária e interesses envolvidos.

PontodeAcesso, Salvador, v. 4, n. 1, p. 78-95, abril. 2010. 
contínua, mnemônica (pela soma dos diversos elementos, principalmente da imagem) e despercebida, num fluxo que não "cansa" a mente do leitor. Este processo se torna vantajoso em uma era de sobrecarga informacional, onde o próprio ato de saber se torna uma urgência para a sobrevivência na sociedade e faz os atores envolvidos sofrerem a chamada ansiedade de informação.

'Pôr-se a par' não implica, forçosamente, uma vigilante consciência crítica no tratamento da torrente. Mas seja qual for a mediocridade [...], regularmente denunciada pelos difamadores da mídia de massas, acontece freqüentemente também que uma informação inesperada se esgueira através da torrente (BOUGNOUX, 1999, p. 142).

O importante é você perceber que, embora não exista uma única visão do que seja informação, há necessidade de um transmissor e de um receptor, ainda que afastados no tempo e no espaço, e que o entendimento de cada um vai determinar o seu significado [...] A mesma pessoa pode perceber a mesma informação de modos diferentes, dependendo não só de quando a recebe, mas também do foco que esteja dando e de sua capacidade de interpretar a simbologia que a acompanha (grifo nosso) (CIANCONI, 2001, p.18).

Na Ciência da Informação, o objeto informação é estudado enquanto representação do conhecimento, podendo ser registrado em um suporte espacial-temporal (LE COADIC, 2004; OLIVEIRA, 2005), definição esta adotada e desenvolvida por grande parte dos autores da área. Farradane (1979 apud SAYÃO, 2000) propõe definir informação como qualquer forma física de representação do conhecimento. Para ele, a informação é o único objeto físico presente na cadeia da comunicação, onde todos os outros estágios são, por natureza, processos mentais, não sendo possível seu exame direto.

As HQs, ao serem submetidas aos critérios necessários para que objetos sejam elevados à categoria de documento, são compreendidas como tal (COSTA, 2009, p. 5-9), caracterizadas por uma determinada linguagem. Segundo Le Coadic (1996), documento é todo artefato que representa um objeto, ideia ou informação através de signos gráficos e icônicos e, para que um documento contenha desinformação, seria necessário que o conhecimento registrado apresentasse informação falsa ou simplesmente fosse ausente (não-informação).

As histórias em quadrinhos, de acordo com os estudos sobre seu conteúdo, não se enquadram nos dois casos, embora sua completa análise "enquanto elementos de 
documentação ainda está para ser feita, bem como o papel que podem desempenhar as instituições da área de informação neste sentido" (VERGUEIRO, 1998, p. 148).

Para tratar dos quadrinhos enquanto documentos é necessário que o profissional da informação compreenda os processos cognitivos que estão neles representados. Esta compreensão torna-se especialmente desafiante na medida em que se percebe que os quadrinhos são compostos de informações textuais, verbais, gestuais etc. formando uma linguagem própria que torna dificultoso seu tratamento e organização por parte do profissional da informação não familiarizado com sua leitura:

[...] a complexidade das histórias em quadrinhos, com 'camadas' de informações sobrepostas umas às outras, caracterizadas pela intertextualidade, na medida em que se conectam a outros textos e formas de leituras, convida-nos a pesquisá-las do ponto de vista da Informação, de maneira a melhor caracterizá-las enquanto fontes de informação para a comunidade. (CAPUTO, 2008)

Ainda se engatinha na elaboração de um cabeçalho de descritores, e as descrições bibliográficas, quando raramente realizadas, não contemplam de forma precisa e detalhada o conteúdo das obras catalogadas, se limitando a esclarecer a forma em que a obra se apresenta - quadrinhos, mas sem explicitar seu conteúdo. Desta forma, não são recuperadas as indicações de responsabilidade, gênero das obras, títulos das histórias, entre outras informações.

O fato de ser um produto da comunicação de massa gera desconfiança quanto ao seu conteúdo ideológico. Na maioria dos casos, porém nota-se que a carga ideológica contida nos quadrinhos não entra em choque com os padrões de conduta social vigentes. Umberto Eco (1976, p. 10) observa que o "Superman jamais estacionará seu carro em local proibido, e nunca fará uma revolução".

Não se deve esperar que as obras em quadrinhos tragam apenas conteúdos e mensagens que corroborem com os padrões comportamentais, culturais, sociais, dogmas e costumes da sociedade em que se encontram, assim como nunca se criou a expectativa de que o mesmo ocorra com outras formas de expressão humana, como a literatura convencional, o teatro e o cinema.

PontodeAcesso, Salvador, v. 4, n. 1, p. 78-95, abril. 2010. 
Gilberto Freyre afirmava ser:

[...] as histórias em quadrinhos uma arma moderna, moderna mas nada secreta, que pode ser posta tanto a serviço de Deus quanto do Diabo. A história em quadrinhos em si não é boa nem má: depende do uso que se faça dela. (FREYRE in ANSELMO, 1975, p. 96).

Um olhar mais atento sobre o mecanismo de construção dos personagens mostra que atitudes e personalidades de ícones aparentemente inocentes evidenciam certo grau de discurso ideológico. A personagem Mônica, de Maurício de Souza, por exemplo, foi objeto de estudo em trabalho de Mendes (1999) que chegou às seguintes conclusões:

Praticamente, não surge nas histórias em quadrinhos da Mônica o trabalhador assalariado, assim como não fica clara, exatamente a ocupação do pai das crianças;

Há quase que total ausência de personagens negras nas histórias da Mônica;

Todas as mães nas histórias em quadrinhos da Mônica não trabalham fora, apenas desempenham tarefas domésticas;

As histórias sustentam-se, em grande maioria, em estereótipos sociais. É o caso, principalmente, das personagens femininas;

Mônica e nenhuma outra personagem da zona urbana estudam;

No universo infantil da personagem, não é dada real importância à ingerência dos adultos. Eles desempenham papel secundário;

Nas histórias em quadrinhos da Mônica predominam personagens da classe média. Assim, os valores difundidos nas HQs dessa personagem são os vinculados à classe média.

Quadro 1

Fonte: Mendes, 1999, p. 4.

Cirne (1982, p. 11) declarava, parafraseando Althusser e Macherey: "não existem quadrinhos inocentes, assim como não existem leitura inocente e livros inocentes". Feijó 
(1997) também provoca a questão: toda história em quadrinhos é arte? Qualquer filme é uma obra de arte?

Como documento, as HQs são "um produto da sociedade que o fabricou segundo relações de força que nela detinham o poder" (LE GOFF, 2000 apud COSTA), não ficando totalmente isentas de influências externas ao seu conteúdo.

Os leitores de quadrinhos, assim como os demais leitores, não estão totalmente livres de influência ideológica; mesmo que o documentalista represente correta e precisamente a informação, ainda assim estará submetendo o usuário ao seu próprio filtro ideológico, através da escolha dos descritores, das classificações temáticas adotadas e dos demais instrumentos de linguagem documentária.

Quem já dirigiu um serviço de informação para qualquer grupo que seja sabe quão importante é pensar de acordo com os valores principais do grupo. É plausível alegar que as pessoas criam sua própria realidade social, que não são as marionetes de comportamentos forçados ou situações de estímulo-resposta. Mesmo assim, seria intelectualmente perverso negar que o mundo físico exerce forte influência no modo como construímos significados para nosso mundo social. (McGARRY, 1999, p.170).

\section{A BARREIRA DA IMAGEM}

Por ser uma linguagem constituída de imagem e texto, os quadrinhos requerem do profissional da informação conhecimentos dos mecanismos de funcionamento de cada um destes dois códigos.

O conhecimento de metodologias de representação de imagens e texto, em separado, será fundamental no processo de elaboração de uma representação documental própria e específica para os quadrinhos, não só realizando a síntese de seu enredo, mas também identificando e indexando estilos, artistas, temas e gêneros etc.

A imagem, por ser, em comparação com o texto, o código informacional mais carente de literatura na área de Ciências da Informação, gera obstáculos para a categorização documental dos quadrinhos.

As imagens são como histórias à espera de um narrador/a. E o espectador/a deve descobrir as histórias explícitas ou secretamente entrelaçadas em todos os tipos de obra de arte. No entanto, nem sempre essas imagens são de fácil leitura, tanto que, para tentar fazer a tradução, é necessário saber a

PontodeAcesso, Salvador, v. 4, n. 1, p. 78-95, abril. 2010. 
senha de acesso, para desvendá-las, tirar as vendas e ler o que subjaz, decifrando assim o sentido oculto. (MANGUEL, 2001, apud CAMARGO, 2004).

Por muito tempo, a Ciência da Informação deteve-se sobre os estudos dos processos de organização e representação da informação através dos documentos impressos, embora a informação visual fosse reconhecida como o mais antigo registro da humanidade.

Ao debruçar-se tardiamente sobre os documentos imagéticos, os teóricos da informação observaram nos suportes como a pintura, a fotografia e as histórias em quadrinhos uma premente necessidade de criação de metodologias que se adequassem às especificidades de cada tipologia. Fazer um corte transversal para a análise da imagem nos quadrinhos gera possibilidades de tratamento documental que não surgem quando se limita este meio de comunicação à sua parte textual.

As imagens, nos quadrinhos, estão em um grau de hierarquia superior às palavras existem quadrinhos sem texto, mas não sem conteúdo imagético. ${ }^{3}$ Cabe recordar que nas tabelas de classificação CDD e CDU, o termo quadrinhos (comics, na versão inglesa) está inserido em Artes, apesar de teóricos defenderem as histórias em quadrinhos como uma forma de literatura.

A imagem integra um discurso visual que, revelando uma faceta da realidade, tornase fonte de informação e objeto de tratamento informacional, podendo ser organizada e representada para fins de obtenção de conhecimento.

Panofsky (2004 apud MAIMONE, 2008) estabelece três níveis de análise da imagem, que, apesar de ter elaborado seu modelo de categorização visando o suporte das pinturas, Smith segue Shatford (1986 apud SMITH, 1996) e afirma ser possível ampliar o escopo de sua proposta para outras imagens, no ambiente da Ciência da Informação. Posteriormente, as teorias de Panofsky foram sistematizadas por Agustin LaCruz :

\footnotetext{
3 Apesar de a imagem constituir a essência dos quadrinhos, não se diz "vou ver quadrinhos" e sim "vou ler quadrinhos"; a partir daí, infere-se que o conceito de leitura adotado pelo leitor desta forma de linguagem previu e precedeu historicamente a atual acepção do termo, no qual leitura pode ser "a ação do telespectador diante da tela [...], a atividade dos usuários da internet [...], dos visitantes de uma exposição de arte contemporânea". (MOURA, apud MAIMONE, 2008).
}

PontodeAcesso, Salvador, v. 4, n. 1, p. 78-95, abril. 2010. 


\begin{tabular}{|c|c|c|c|c|}
\hline $\begin{array}{c}\text { Niveis de } \\
\text { Análise }\end{array}$ & Tipo de Análise & Objeto de Análise & $\begin{array}{c}\text { Operações } \\
\text { Analítico- } \\
\text { sintéticas }\end{array}$ & $\begin{array}{c}\text { Conhecimentos } \\
\text { requeridos }\end{array}$ \\
\hline Primário & Pré-iconográfico & $\begin{array}{l}\text { Pessoas, animais, } \\
\text { objetos, acontecimentos e } \\
\text { suas propriedades e } \\
\text { relações }\end{array}$ & Descrição & $\begin{array}{c}\text { Experiência cotidiana e } \\
\text { cultura geral }\end{array}$ \\
\hline Secundário & Iconográfico & $\begin{array}{l}\text { Temas e conceitos, } \\
\text { histórias, alegorias, etc. }\end{array}$ & Identificação & $\begin{array}{c}\text { Conhecimentos dos } \\
\text { temas e formas } \\
\text { artísticas }\end{array}$ \\
\hline Terciário & Iconológico & $\begin{array}{l}\text { Princípios socioculturais } \\
\text { subjacentes }\end{array}$ & Interpretação & $\begin{array}{c}\text { Conhecimento profundo } \\
\text { da sociedade a cultura } \\
\text { e a cosmovisão de cada } \\
\text { época }\end{array}$ \\
\hline
\end{tabular}

Figura 1

Fonte: Agustin LaCruz (1996) apud Maimone (2008).

O primeiro nível requer conhecimentos superficiais, suficientes para a descrição objetiva do que está representado na imagem.

O terceiro nível (iconológico) demanda, do profissional da informação, amplos conhecimentos do contexto sociocultural em que a imagem foi gerada, visando a correta interpretação dos motivos e características de sua existência.

O nível secundário é o que demanda maior dificuldade no tratamento documentário dos quadrinhos e demais suportes imagéticos, pois implica em identificar o tema e estilos artísticos, exigindo do documentalista certo conhecimento da linguagem.

Como quadrinhos são sequências de imagens no mesmo espaço, o primeiro nível se torna inócuo nesta forma de análise, pois só seria possível na descrição de uma unidade imagética, como um cartum, uma charge, uma pintura ou uma fotografia, e não num grupo de imagens - essência dos quadrinhos. O que não impede de ser realizado, se os componentes do conjunto imagético possuírem vários elementos em comum, como mostrado na figura 3.

Para ilustrar como o conhecimento em nível iconográfico poderia refletir no tratamento documental dos quadrinhos, cabe aqui alguns exemplos: 


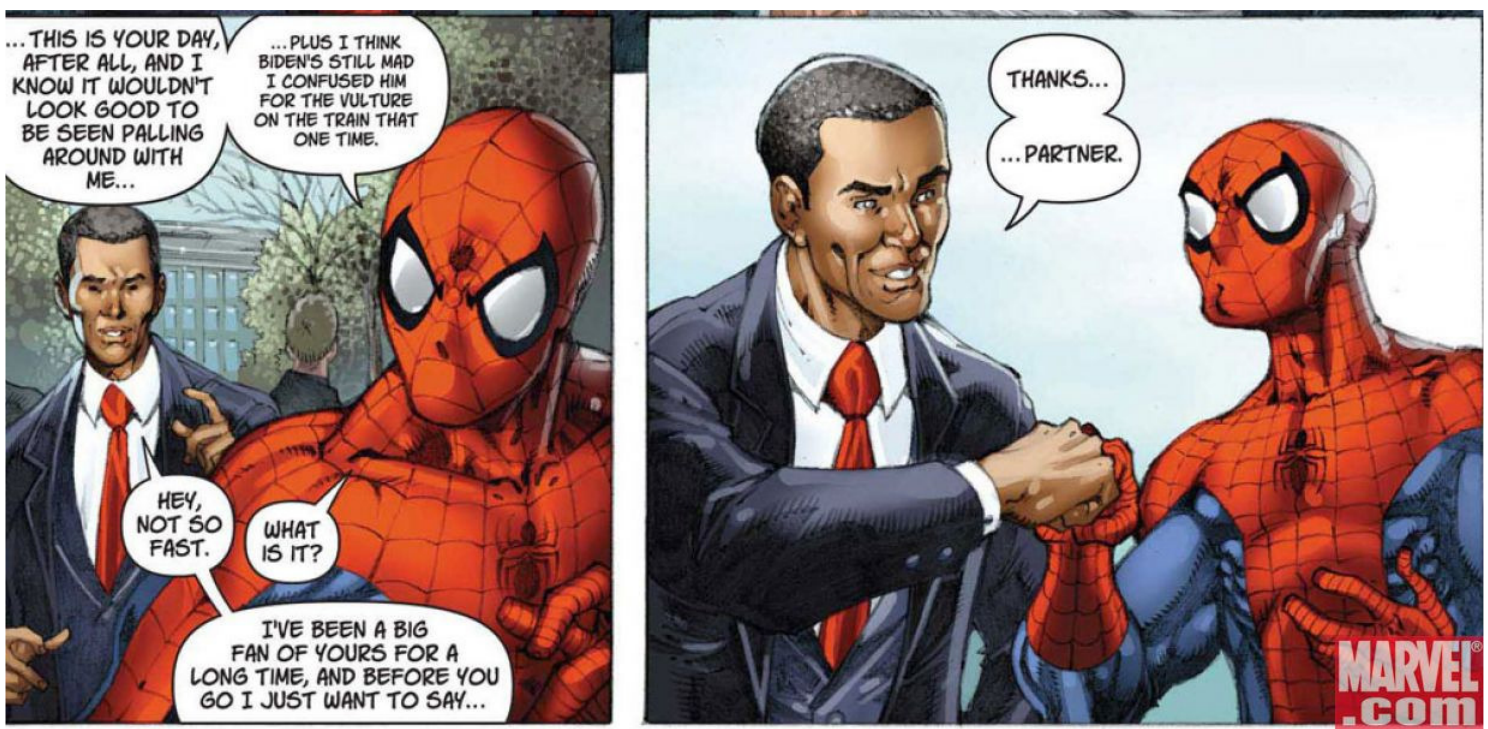

Figura 2

Fonte: Something like a rapper [2010].

- Pré-iconográfico: Duas pessoas, uma delas fantasiada, dialogando - descrição comum às duas vinhetas;

- Iconográfico: O super-herói Homem-Aranha desejando bom mandato ao presidente Barack Obama, logo após a eleição;

- Iconológico: História em quadrinhos retratando um momento histórico ocorrido no ano de 2008, quando foi eleito o primeiro presidente negro dos Estados Unidos.

Ao tentar recuperar a obra em quadrinhos que contém estes dois requadros, seria necessário certo conhecimento iconográfico, no sentido de saber que o fantasiado é o Homem-Aranha e que estaria numa revista de super-heróis. Um completo leigo em quadrinhos não saberia distinguir um herói de um vilão. 


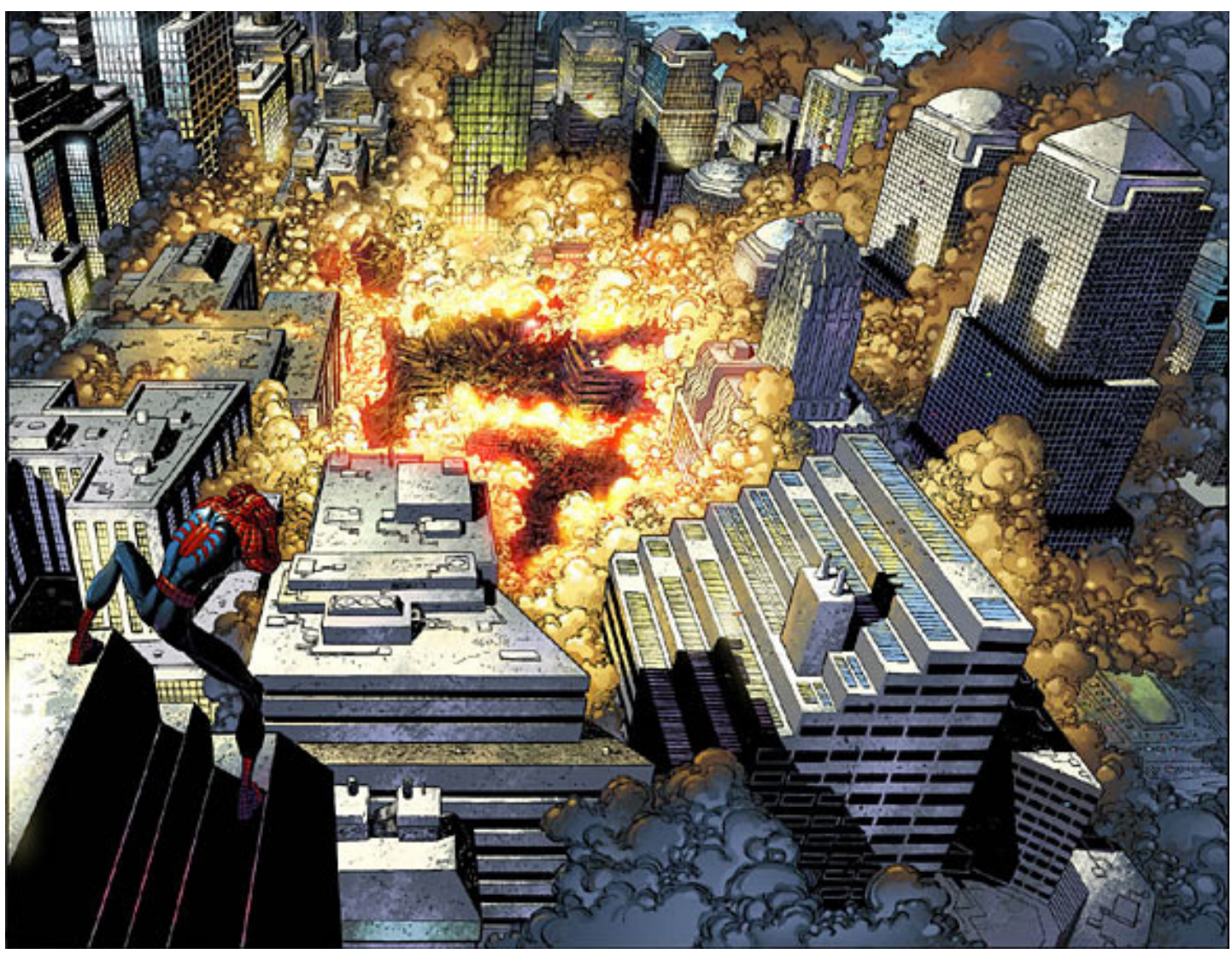

Figura 3

Fonte: Comic Book Resouces [2010].

- Pré-iconográfico: Uma pessoa fantasiada, no alto de um prédio, observa escombros numa avenida em frente;

- Iconográfico: O super-herói Homem-Aranha se desespera em frente aos escombros das torres do Word Trade Center, logo após o atentado que derrubou-as;

- Iconológico: História em quadrinhos retratando um momento histórico ocorrido no ano de 2001, quando terroristas utilizaram aviões comerciais para chocá-los contra edificações americanas.

Estes dois exemplos, abordando fatos reais sob uma linguagem artística, demonstram como os quadrinhos, fenômeno que "criou o campo iconográfico mais vasto e rico que a história conhece" (COUPÉRIE, 1970 apud ANSELMO, p. 32), não estão ausentes ao contexto social no momento de sua criação e produção, e como o conteúdo informativo presente neste meio pode estar sendo ignorado e desprivilegiado como fonte de informação. 
[...] nas histórias em quadrinhos, as personagens, a forma gráfica e a linguagem verbal expressam, carregam e estão imbricados na Cultura no mais amplo sentido, sendo sub-utilizadas, quer nas instituições encarregadas de disseminar informações (caso das bibliotecas), quer em escolas, onde poderiam incentivar outros tipos de leitura. As histórias em quadrinhos por si só, estão vinculadas a sua linguagem rica e densa em conteúdo e símbolos gráficos. (CAPUTO, 2008).

Quanto à representação da parte textual dos quadrinhos, um sistema como o Precis ${ }^{4}$, de indexação alfabética de assunto, com ênfase na ação, característica própria desta linguagem, se mostraria o mais adequado à síntese das narrativas.

O Precis trata a síntese do resumo a partir dos seguintes questionamentos: o que aconteceu? (ação); a que ou a quem aconteceu? (objeto da ação); o que ou quem fez isto? (agente da ação); onde aconteceu isto? (local da ação). Nas sinopses das chamadas publicitárias sobre quadrinhos, pode-se perceber que esta é linha adotada pelos editores para divulgar as histórias.

\section{REFLEXOS EM BIBLIOTECAS E ESPAÇOS DE LEITURA}

Os quadrinhos carecem, no momento, de modelos de linguagem documentária que se aplique as suas características. Com isso, ao lidar com este tipo de coleção em seus acervos, o profissional da área tende a pular a etapa de descrição do conteúdo (também chamado de análise documentária) e imediatamente faz o armazenamento. Na melhor das hipóteses, é feita a descrição bibliográfica através da catalogação. A classificação, quando realizada, não identifica o assunto e sim o tipo da obra (história em quadrinhos) e a indexação, parte da análise documentária e importante na identificação da obra, raramente é efetuada com detalhes.

$\mathrm{Na}$ escassez de procedimentos de representação documentária e de literatura na área, os quadrinhos ficam limitados, nas unidades de informação, a só uma parte do ciclo proposto por Dodebei (2002), o subconjunto informação:

\footnotetext{
${ }^{4}$ Idealizado por Derek Austin em 1986.

PontodeAcesso, Salvador, v. 4, n. 1, p. 78-95, abril. 2010. 


\section{Ciclo da Informação}

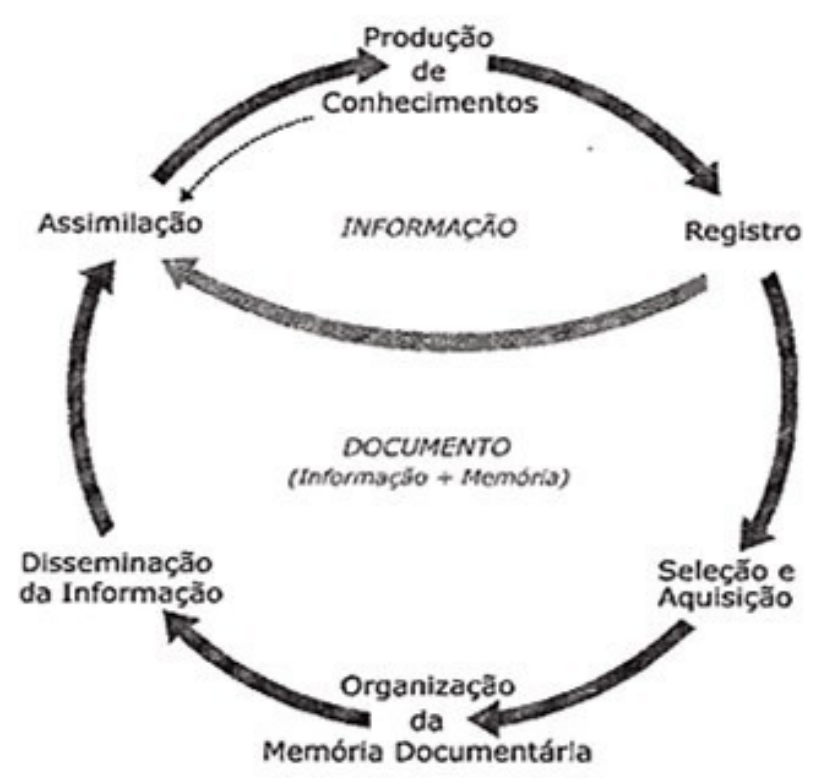

Figura 4

Fonte: Dodebei (2002, p. 25)

Suportes que demandam uma análise mais singular, e requer conhecimentos específicos, como ocorre com os quadrinhos, não circulam em todo o ciclo, sendo subaproveitados em seu potencial.

Vergueiro [2009] relaciona algumas evidências deste tratamento:

[...] não incorporação definitiva ao acervo, o descarte generalizado e a despreocupação com o estabelecimento de critérios de seleção, bem como serem objeto de restrições quanto à sua aquisição com recursos próprios ou quanto ao uso por todas as categorias de usuários (proibindo-se o acesso a usuários de determinadas faixas etárias, por exemplo), [...] são utilizadas pelos profissionais de informação como um chamariz para a leitura de livros, uma espécie de concessão dos profissionais a uma leitura menor.

\section{CONSIDERAÇÕES FINAIS}

A prática de representar é a ponte que aproxima a informação em estado bruto e o usuário, transpondo quaisquer barreiras que possam impedir o uso da informação, sejam elas cognitivas, geográficas, linguísticas, entre outras. Nos quadrinhos, porém, a informação 
encontra-se submersa num meio eminentemente comunicativo, e, quando vêm á tona, não se torna atualmente objeto de representação por parte dos profissionais de informação.

Como consequência, forma-se um ciclo vicioso, pois não são geradas linguagens documentárias específicas e não se sugere formas de potencializar os recursos presentes nesta forma de literatura.

Por vir entremeada de símbolos textuais e imagéticos, numa combinação singular que não encontra par em outra forma de comunicação, a informação nos quadrinhos tem um poder mnemônico mais eficiente e particularmente atrativo para os usuários. Porém, esta mesma característica que a torna especial também a torna mais dificultosa de representar para fins de recuperação, ficando as obras em quadrinhos simplesmente agrupadas em estantes sem outro critério de organização a não ser sua forma.

Deveria a informação nos quadrinhos, por estar num suporte mais peculiar, ser objeto de mais investigação e estudo, e não o contrário; afinal, cabe justamente ao profissional, através de técnicas de representação documental, tornar uma informação complexa mais palatável ao leitor.

Cabe também aos bibliotecários, como atores sociais envolvidos na ação da leitura, agir no sentido de atender o público consumidor de obras em quadrinhos, que já tem uma relação quase umbilical com elas, por terem se constituído em algum momento da sua infância nas primeiras impressões de leitura e que atualmente são órfãos de espaços onde possam exercer esta atividade com respeito e ausência de preconceito.

As imagens e o campo de estudo foram aqui eleitos como impeditivos para o desenvolvimento de técnicas de representação documental de quadrinhos, porém não pretendendo excluir a existência de outras, como o preconceito, por exemplo; fazer um corte transversal para estes elementos foi necessário para apontar vieses discursivos e direcionar os debates, o que por si só já terá sido o objetivo principal deste trabalho. 


\section{REFERÊNCIAS}

ANDRAUS, Gazy. As histórias em quadrinhos como informação imagética integrada ao ensino universitário. $321 \mathrm{f}$. Tese (Doutorado em Ciências da Comunicação) - Universidade de São Paulo, Escola de Comunicações e Artes, São Paulo, 2006. Disponível em:

<http://www.guiadosquadrinhos.com/upload/monografias/2006_Tese_andraus_gazy_2.pdf > Acesso em: 08 set. 2009.

ANSELMO, Zilda Augusta. Histórias em quadrinhos. Petrópolis, RJ: Vozes, 1975.

BOUGNOUX, Daniel. Introdução às Ciências da Comunicação. Tradução Maria Leonor Loureiro. Bauru, SP: EDUSC,1999.

CAMARGO, Maria Aparecida Santana. Alfabetização imagética: uma forma de construção da própria cidadania. Disponível em: <http://www.cereja.org.br/site/noticia.asp?id=1667> Acesso em: 08 set. 2009.

CAPUTO, Maria Alice Romano. Histórias em quadrinhos: um potencial de informação inexplorado. Disponível em: <http://www.festivaldearte.fafcs.ufu.br/2005/comunicacao21.htm> Acesso em: 08 set. 2009.

CIANCONI, Regina. Gestão da informação na sociedade do conhecimento. Brasília: SENAI, 1999.

CIRNE, Moacy. Para ler os quadrinhos: da narrativa cinematográfica à narrativa quadrinizada. Petrópolis: Vozes, 1972.

A explosão criativa dos quadrinhos. 5. ed. Petrópolis: Vozes, 1977. (Vozes do mundo moderno, 8)

. Uma introdução política aos quadrinhos. Rio de Janeiro: ANGRA / ACHIAMÉ, 1982.

COMIC BOOK RESOUCES [2010]. Disponível em: http://images.comicbookresources.com/ previews/asm36/wtc3.jpg > Acesso em: 22 mar. 2010.

COSTA, Robson Santos; ORRICO, Evelyn G. Dill. Informação, memória e documento: o caso das histórias em quadrinhos. Disponível em:

<http://www. portalppgci.marilia.unesp.br/enancib/viewpaper.php?id=259>. Acesso em: 08 set. 2009.

DODEBEI, Vera Lúcia Doyle. Tesauro: linguagem de representação da memória documentária. Niterói: Intertexto; Rio de Janeiro: Interciência, 2002.

ECO, Umberto. Apocalípticos e integrados. 5. ed. São Paulo: Perspectiva, 1993. (Debates, 19).

EISNER, Will. Quadrinhos e arte seqüencial. São Paulo: Martins Fontes, 1989.

PontodeAcesso, Salvador, v. 4, n. 1, p. 78-95, abril. 2010. 
FEIJÓ, Mário. Quadrinhos em ação: um século de história. 2. ed. São Paulo: Moderna, 1997. (Polêmica).

LE COADIC, Yves-François. A ciência da informação. Tradução de Maria Yêda F. S. de Filgueiras Gomes. Brasília, DF: Briquet de Lemos, 2004.

MAIMONE, Giovana Deliberali; TÁLAMO, Maria de Fátima Gonçalves Moreira. Tratamento informacional de imagens artístico-pictóricas no contexto da Ciência da Informação.

DataGramaZero: Revista de Ciência da Informação, São Paulo, v.9, n.2, abr./2008. Disponível em: http://dgz.org.br/abr08/F_I_art.htm. Acesso em: 04 out. 2009.

; GRACIOSO, Luciana de Souza. Representação temática de imagens: perspectivas metodológicas. Informação e Informação, Londrina, v.12, n.1, jan./jun.2007. Disponível em: <http://www.uel.br/revistas/uel/index.php/informacao/article/view/1760/1504>. Acesso em: 04 out. 2009.

McGARRY. $O$ contexto dinâmico da informação: uma análise introdutória. Brasília: Briquet de Lemos, 1999.

McCLOUD, Scott. Desvendando os quadrinhos. Tradução de Hélcio de Carvalho e Marisa do Nascimento Paro. São Paulo: Makron Books, 1995.

MENDES, Marcília Luzia Gomes da Costa. Fragmentos do discurso quadrinizado: uma leitura crítica da personagem Mônica. Disponível em:

<http://dci2.ccsa.ufpb.br:8080/jspui/bitstream/123456789/346/1/v9_n2_1999_9.pdf>.

Acesso em: 08 set. 2009.

OLIVEIRA, Marlene de. Origens e evolução da ciência da informação. In: CENDÓN, Beatriz Valadares et al; OLIVEIRA, Marlene de (Coord.). Ciência da Informação e Biblioteconomia: novos conteúdos e espaços de atuação. 1. reimp. Belo Horizonte, Editora UFMG, 2008.

PANOFSKY, Erwin. Significado nas artes visuais. 3. ed. São Paulo: Perspectiva, 2004. (Debates, 99)

SAYÃO, Luís Fernando. Bases de dados e suas qualidades. In: LUBISCO, Nídia M. L.; BRANDÃO, Lídia M. B. (Org.). Informação e informática. Salvador: EDUFBA, 2000.

SMIT, Johanna W. A representação da imagem. Informare: Cadernos do Programa de PósGraduação em Ciência da Informação, Rio de Janeiro, v. 2, n. 2, p. 28-36, jul./dez. 1996.

SOMETHING LIKE A RAPPER. Disponível em: <http://somethinglikearapper.files. wordpress.com/2009/01/2009-01-08-spideyobama12.jpg >. Acesso em: 22 mar. 2010.

STUMPF, Ida Regina; WEBER, Maria Helena. Comunicação e informação: conflitos e convergências. In: LOPES, Maria Immacolata Vassalo da (Org.). Epistemologia da Comunicação. São Paulo: Edições Loyola, 2003. p. 121-134. (Comunicação Contemporânea).

PontodeAcesso, Salvador, v. 4, n. 1, p. 78-95, abril. 2010. 
VERGUEIRO, Waldomiro. Histórias em quadrinhos. In: CAMPELLO, Bernadete; CALDEIRA, Paulo da Terra; MACEDO, Vera Amália Amarante (Org.). Formas e expressões do conhecimento: introdução às fontes de informação. Belo Horizonte: Escola de Biblioteconomia da UFMG, 1998, p. 117-149.

. Uso das HQs no ensino. In: RAMA, Ângela; VERGUEIRO, Waldomiro (Org.). Como usar as histórias em quadrinhos na sala de aula. 3. ed. São Paulo: Contexto, 2007. p. 7-29. (Coleção Como usar na sala de aula).

. Não está no gibi. [2009]. Disponível em:

<http://www.ofaj.com.br/colunistas.php?cod=9>. Acesso em: 08 set. 2009.

Histórias em quadrinhos e serviços de informação: um relacionamento em fase de definição. DataGramaZero: Revista de Ciência da Informação, São Paulo, v. 6, n. 2, abr. 2005. Disponível em:

<http://dici.ibict.br/archive/00000357/01/Hist\%C3\%B3rias_em_quadrinhos_e_servi\%C3\%A7 os_de_informa\%C3\%A7\%C3\%A3o.pdf> Acesso em: 08 set. 2009. 